Trauma Surgery \& Acute Care Open

\title{
Prehospital resuscitation
}

\author{
Alexandra M P Brito, ${ }^{1}$ Martin Schreiber ${ }^{2}$
}

'Surgical Critical Care, Oregon Health \& Science University, Portland, Oregon, USA ${ }^{2}$ Surgery, Oregon Health and Science University, Portland, Oregon, USA

\section{Correspondence to} Dr Alexandra M P Brito; a.brito 26@gmail.com

Received 1 March 2021 Revised 31 March 2021 Accepted 9 April 2021 (c) Author(s) (or their employer(s)) 2021. Re-use permitted under CC BY-NC. No commercial re-use. See rights and permissions. Published by BMJ.

\section{To cite:}

Brito AMP, Schreiber M.

Trauma Surg Acute Care Open 2021:6:e000729.

\section{SUMMARY}

Traumatic injury is the leading cause of death in young people in the USA. Our knowledge of prehospital resuscitation is constantly evolving and is often informed by research based on military experience. A move toward balanced blood product resuscitation and away from excessive crystalloid use has led to improvements in outcomes for trauma patients. This has been facilitated by new technologies allowing more front-line use of blood products as well as use of tranexamic acid in the prehospital setting. In this article, we review current practices in prehospital resuscitation and the studies that have informed these practices.

\section{INTRODUCTION}

Traumatic injury is the leading cause of death in the USA for patients up to age 44 years. ${ }^{1}$ From the time of injury to definitive hemorrhage control, there are many opportunities to improve the ultimate outcome by minimizing physiological derangements with resuscitation as early in the course as possible. Acute traumatic coagulopathy (ATC) is the process by which the effects of severe injury combined with tissue hypoperfusion leads to a cycle of acidosis, hypothermia, and hemodilution from crystalloid resuscitation, which has low $\mathrm{pH}$, high chloride, no oxygen carrying capacity and no coagulation capacity correction. This leads to inflammatory changes, hyperfibrinolysis, endothelial dysfunction, dysfibrinogenemia, and platelet dysfunction. ${ }^{2}$ These changes exacerbate uncontrolled hemorrhage and organ dysfunction, feeding back into a self-perpetuating process which if not interrupted leads to a fatal outcome. Intervention on this lethal cycle by appropriate resuscitation should start as early as possible, ideally at the time of first contact with healthcare providers.

\section{MILITARY EXPERIENCE WITH PREHOSPITAL RESUSCITATION}

Much of our current knowledge of resuscitation in major trauma is based on military experience. The Committee on Tactical Combat Casualty Care (CoTCCC) is part of the Defense Health Agency Joint Trauma System that develops guidelines for management of injured warfighters in the field. ${ }^{3}$ Hemorrhagic shock is recognized by the presence of altered mental status in the absence of brain injury and/or weak or absent radial pulses. ${ }^{4}$ Fluid resuscitation is reserved for patients in shock, and the order of fluid priority is (1) liquid cold stored low-titer O whole blood; (2) prescreened low-titer O fresh whole blood (from a 'walking blood bank'); (3) plasma, red blood cells (RBCs) and platelets in a 1:1:1 ratio; (4) plasma and RBCs in a $1: 1$ ratio; and (5) plasma or RBCs alone. Crystalloids are not listed in this protocol.

\section{TIMING OF CRYSTALLOID RESUSCITATION}

Unlike the well-established process within the military to make blood products available out of hospital, few prehospital emergency medical service (EMS) agencies have access to RBCs and plasma where the majority only have crystalloid fluid available for resuscitation. As crystalloid is not ideal for replacing blood loss, a question arises of whether crystalloid is helpful or harmful in the early stages of resuscitation. A study by Bickell et al in $1994^{5}$ examined the effects of delaying fluid resuscitation until definitive hemorrhage control was obtained in hypotensive patients with penetrating torso injuries. This was a prospective study of patients with prehospital systolic blood pressure (SBP) less than $90 \mathrm{~mm} \mathrm{Hg}$ in which patients were randomized to immediate standard fluid resuscitation versus no fluid. The intervention started in the field and continued until hemorrhage was controlled. Labs on arrival including hemoglobin, platelets, prothrombin time (PT) and partial thromboplastin time (PTT) were consistent with a greater degree of anemia and coagulopathy in the immediate resuscitation group. In the delayed resuscitation group, $70 \%$ survived versus $62 \%$ in the standard group $(p=0.04)$. Whereas the intraoperative blood transfusion volume was similar in the two groups, the rate of intraoperative fluid administration was greater in the immediate group, and the total fluids and blood products administered was significantly higher in the immediate group. The delayed resuscitation group also showed a trend toward fewer complications and had a significant reduction in length of hospital stay.

\section{VOLUME OF CRYSTALLOID RESUSCITATION}

The Resuscitation Outcomes Consortium consisted of multiple trauma systems in North America (figure 1). This group performed a prospective randomized trial starting in the field where hypotensive patients were assigned to either standard resuscitation where patients received $2 \mathrm{~L}$ of normal saline immediately and were transitioned to TKVO (the lowest volume possible "to keep [the] vein open”) if the SBP was $\geq 110 \mathrm{~mm} \mathrm{Hg}$ or ongoing boluses if the SBP was $\leq 110 \mathrm{~mm} \mathrm{Hg}$, compared with a controlled resuscitation protocol of $250 \mathrm{~mL}$ boluses for a SBP $<70$ or absence of a radial pulse. ${ }^{6}$ The protocol was continued until hemorrhage control was achieved or for up to 2 hours in hospital. Nineteen EMS units and 10 hospitals participated in this study in six regions of North America. Whereas no significant difference was seen in mortality in patients with penetrating trauma, patients with blunt injuries 

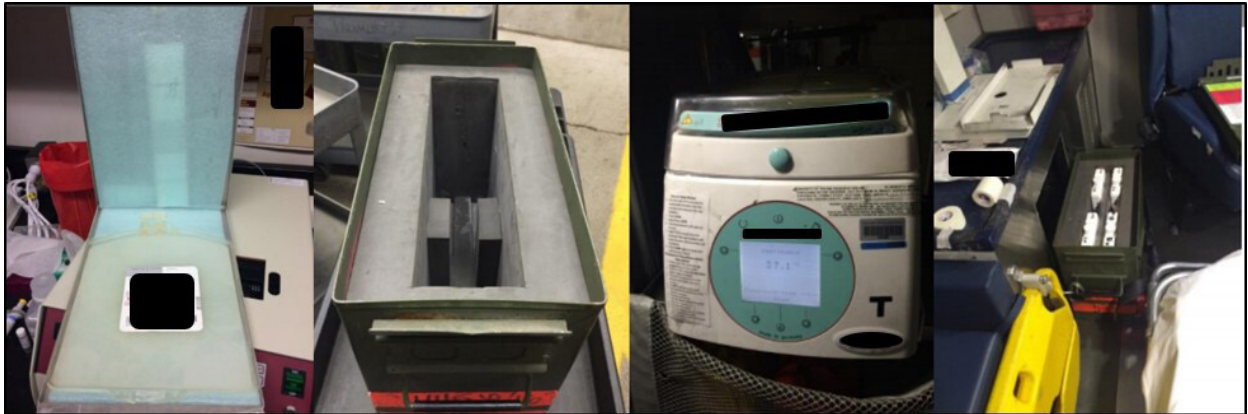

Figure 1 Plasma storage and quick thawing device.

had significantly lower 24-hour mortality if randomized to the controlled resuscitation group.

\section{PREHOSPITAL BLOOD PRODUCT RESUSCITATION}

The Prehospital Air Medical Plasma (PAMPer) trial ${ }^{7}$ was a multicenter cluster randomized trial comparing prehospital administration of thawed plasma compared with standard crystalloid resuscitation during air transport to trauma centers. Mortality at 30 days was significantly lower in the plasma group (almost 10\% improvement). International normalized ratio (INR) was significantly lower in the plasma group and there were no differences in multiple organ failure, acute lung injury/ acute respiratory distress syndrome, nosocomial infections, or allergic/transfusion reactions. This study also showed that the volume of prehospital crystalloid and RBC administration was significantly lower in the plasma group. The Control of Major Bleeding After Trauma Trial (COMBAT) trial ${ }^{8}$ done the same year was a single center randomized trial comparing up to two units of FFP to standard normal saline resuscitation initiated in the field in patients with SBP of $<70 \mathrm{~mm} \mathrm{Hg}$ or $71 \mathrm{~mm} \mathrm{Hg}$ to $90 \mathrm{~mm} \mathrm{Hg}$ plus HR of $>108$. Plasma units contained in modified bags with a large surface area were maintained frozen on ground ambulances and thawed within 3 minutes to 4 minutes using a thermal device (figure 2). This study showed no significant difference in baseline characteristics, 28-day mortality, safety outcomes or adverse events. However, the average transport time was less than 20 minutes in the COMBAT trial. In the PAMPer trial, subgroup analysis showed no mortality benefit of plasma in patients with short transport times, whereas those with 'prolonged' prehospital transport times did have increased survival with plasma. However, the definition of prolonged versus short transport time was not explicitly stated in this article.

A recent review of prehospital blood transfusion found that when plasma and packed red blood cells (pRBCs) were transfused concurrently a significant improvement of long-term mortality was seen, although this was not the case with 24-hour mortality, and pRBCs transfused alone did not show any mortality benefit. ${ }^{9}$ Within the military population, prehospital blood product transfusion in Afghanistan was associated with greater 24-hour and 30-day survival compared with delayed or no transfusion. ${ }^{10}$ The majority of these patients received only pRBCs, and as such, there may be room for improvement with more balanced blood product transfusion. One way some systems have moved toward this is with increased availability of whole blood. Low-titer type O whole blood (LTOWB) was to lead to less out of emergency department transfusion and when corrected for severity of injury and other confounders was associated with a twofold likelihood of survival. ${ }^{11}$ Whole blood is now the preferred resuscitative fluid of the $\mathrm{CoTCC}^{3}$ and despite the challenges associated with temperature requirements, cold stored LTOWB has been effectively transported to and used in austere military environments ${ }^{12}$ with favorable results shown in a case series. ${ }^{13}$ Civilian experience with prehospital whole blood transfusion is still limited. One regional program has been established in Texas and although mortality data has not been published the cost-benefit balance seems to be favorable. ${ }^{14-16}$
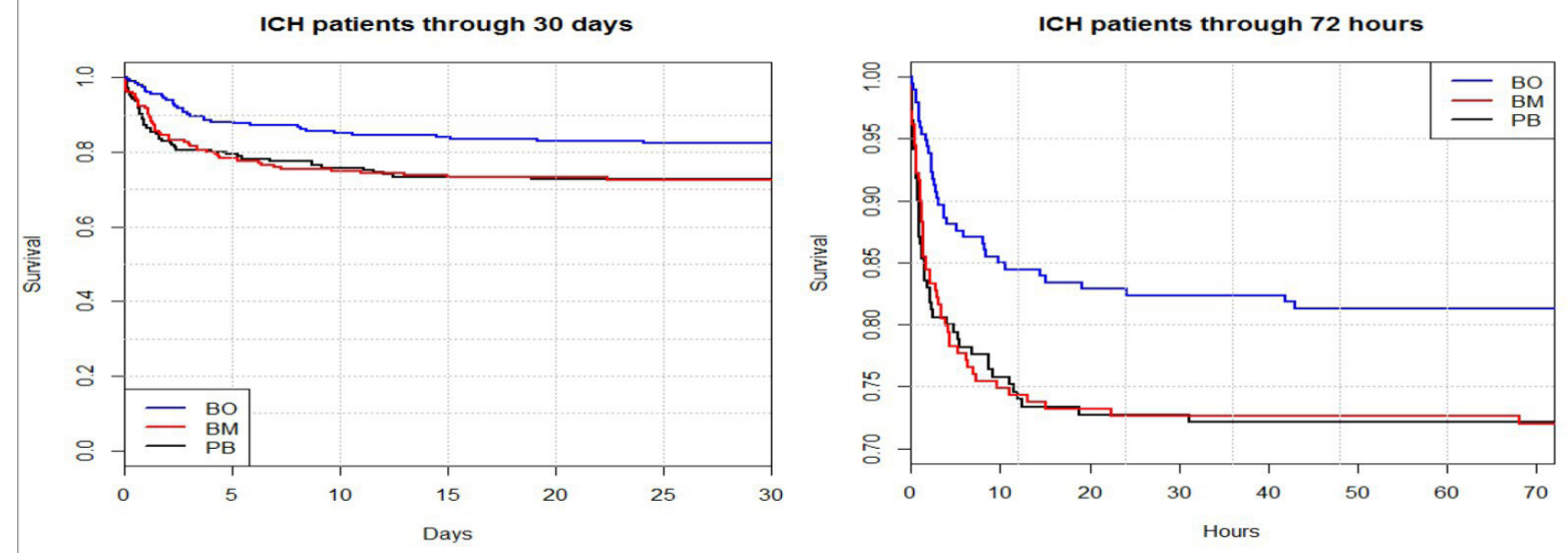

Figure 2 Two-gram TXA BO, $1 \mathrm{~g}$ TXA BM, PB survival comparison (data from Rowell et al, ${ }^{19}$ figure not previously published). BM, bolus plus maintenance; BO, bolus only; ICH, intracerebral hemorrhage; PB, placebo bolus only; TXA, tranexamic acid. 
Prehospital tranexamic acid (TXA)

The CRASH-2 trial was a randomized controlled trial comparing tranexamic acid (TXA) (1 g bolus started by EMS followed by a $1 \mathrm{~g}$ in hospital infusion) to placebo for patients with significant hemorrhage or risk for significant hemorrhage. ${ }^{17}$ A small mortality benefit was seen in patients who received treatment within 3 hours of injury. The benefit was greatest the earlier TXA was given and there was a signal of benefit in TBI. CRASH 3 was a follow-up study which focused on outcomes in TBI where TXA or placebo was administered within 3 hours of injury. ${ }^{18}$ There was a small decrease in head injury-related death in mild to moderate head injury but not severe head injury, with all other outcomes examined being similar between groups. A recent randomized multicenter study by Rowell et al examined outcomes in patients with moderate or severe traumatic brain injury who received either $2 \mathrm{~g}$ of TXA in the out of hospital setting versus $1 \mathrm{~g}$ out of hospital plus a $1 \mathrm{~g}$ in hospital infusion versus placebo. ${ }^{11}$ The primary analysis assessing all enrolled patients did not show a difference in survival or 6 months' neurological outcome. A planned secondary analysis on patients who had intracranial bleeding on admission head CT revealed a significant survival advantage which primarily occurred during the first 10 hours after injury. (figure 2). In this secondary analysis, patients who received $2 \mathrm{~g}$ of TXA also had improved 6 month neurological outcome. In the California Prehospital Antifibrinolytic Therapy (Cal-PAT) study, another randomized multicenter study, mortality in the group that received TXA $1 \mathrm{~g}$ bolus and $1 \mathrm{~g}$ in hospital infusion) was significantly reduced at 28 days, although there was no significant difference at 24 or 48 hours (Neeki). The mortality difference was greatest in more severely injured patients. All patients required less blood transfusion after TXA administration, and no difference in adverse events was seen between groups. Based on these data, the CoTCCC has changed their guidelines to include $2 \mathrm{~g}$ of TXA for patients in hemorrhagic shock or those with TBI in the field.

\section{CONCLUSION}

Prehospital resuscitation is continuously evolving. Blood product resuscitation is particularly beneficial with long transport times to prevent the initiation and progression of ATC. Crystalloid is not a preferred resuscitation for hemorrhagic shock unless blood products are not available and the patient is in shock. In this situation, only enough crystalloid to maintain organ perfusion should be given. TXA should be given as a resuscitation adjunct in the field to patients with hemorrhagic shock or TBI. Today's special forces medics carry LTOWB, cold stored platelets, lyophilized plasma and TXA to optimize prehospital resuscitation, a combination of resources that is more than some level 1 trauma centers. More research into novel blood product resuscitation in the out of hospital setting is needed.

Contributors MS: author of original presentation, edits. AMPB: transcription/ translation into article, additional references and formatting figures.

Funding The authors have not declared a specific grant for this research from any funding agency in the public, commercial or not-for-profit sectors.

Map disclaimer The depiction of boundaries on the map(s) in this article does not imply the expression of any opinion whatsoever on the part of BMJ (or any member of its group) concerning the legal status of any country, territory, jurisdiction or area or of its authorities. The map(s) are provided without any warranty of any kind, either express or implied.

Competing interests None declared.

Patient consent for publication Not required.

Provenance and peer review Not commissioned; externally peer reviewed.
Open access This is an open access article distributed in accordance with the Creative Commons Attribution Non Commercial (CC BY-NC 4.0) license, which permits others to distribute, remix, adapt, build upon this work non-commercially, and license their derivative works on different terms, provided the original work is properly cited, appropriate credit is given, any changes made indicated, and the use is non-commercial. See: http://creativecommons.org/licenses/by-nc/4.0/.

\section{REFERENCES}

1 CDC 10 Leading Causes of Death, United States. All Races, Both Sexes. 2019. https:// webappa.cdc.gov/sasweb/ncipc/leadcause.html (Feb 2021).

2 Hess JR, Brohi K, Dutton RP, Hauser CJ, Holcomb JB, Kluger Y, Mackway-Jones K, Parr MJ, Rizoli SB, Yukioka T, et al. The coagulopathy of trauma: a review of mechanisms. J Trauma 2008;65:748-54.

3 Joint Trauma System. The Department of Defense Center of Excellence for Trauma, Committee on Tactical Combat Casualty Care. https://jts.amedd.army.mil/index.cfm/ committees/cotccc (Feb 2021).

4 Deployed Medicine. TCCC Guidelines. https://books.allogy.com/web/tenant/8/books/ b729b76a-1a34-4bf7-b76b-66bb2072b2a7/ (Feb 2021).

5 Bickell WH, Wall MJ, Pepe PE, Martin RR, Ginger VF, Allen MK, Mattox KL. Immediate versus delayed fluid resuscitation for hypotensive patients with penetrating torso injuries. N Engl J Med 1994:331:1105-9.

6 Schreiber MA, Meier EN, Tisherman SA, Kerby JD, Newgard CD, Brasel K, Egan D, Witham W, Williams C, Daya M, et al. A controlled resuscitation strategy is feasible and safe in hypotensive trauma patients: results of a prospective randomized pilot trial. I Trauma Acute Care Surg 2015;78:687-97.

7 Sperry JL, Guyette FX, Brown JB, Yazer MH, Triulzi DJ, Early-Young BJ, Adams PW, Daley BJ, Miller RS, Harbrecht BG, et al. Prehospital plasma during air medical transport in trauma patients at risk for hemorrhagic shock. N Eng/ J Med 2018;379:315-26.

8 Moore HB, Moore EE, Chapman MP, McVaney K, Bryskiewicz G, Blechar R, Chin T, Burlew CC, Pieracci F, West FB, et al. Plasma-first resuscitation to treat haemorrhagic shock during emergency ground transportation in an urban area: a randomised trial. Lancet 2018;392:283-91.

9 Rijnhout TWH, Wever KE, Marinus RHAR, Hoogerwerf N, Geeraedts LMG, Tan ECTH. Is prehospital blood transfusion effective and safe in haemorrhagic trauma patients? A systematic review and meta-analysis. Injury 2019;50:1017-27. May.

10 Shackelford SA, Del Junco DJ, Powell-Dunford N, Mazuchowski EL, Howard JT, Kotwal RS, Gurney J, Butler FK, Gross K, Stockinger ZT. Association of prehospital blood product transfusion during medical evacuation of combat casualties in Afghanistan with acute and 30-day survival. JAMA 2017;318:1581-91.

11 Williams J, Merutka N, Meyer D, Bai Y, Prater S, Cabrera R, Holcomb JB, Wade CE, Love JD, Cotton BA. Safety profile and impact of low-titer group 0 whole blood for emergency use in trauma. J Trauma Acute Care Surg 2020:88:87-93.

12 Vanderspurt CK, Spinella PC, Cap AP, Hill R, Matthews SA, Corley JB, Gurney JM. The use of whole blood in US military operations in Iraq, Syria, and Afghanistan since the introduction of low-titer type 0 whole blood: feasibility, acceptability, challenges. Transfusion 2019:59:965-70.

13 Fisher AD, Miles EA, Broussard MA, Corley JB, Knight R, Remley MA, Cap AP, Gurney $J M$, Shackelford SA. Low titer group 0 whole blood resuscitation: military experience from the point of injury. J Trauma Acute Care Surg 2020;89:834-41.

14 Pokorny DM, Braverman MA, Edmundson PM, Bittenbinder DM, Zhu CS, Winckler CJ, Schaefer R, McGinity AC, Epley E, Eastridge BJ, et al. The use of prehospital blood products in the resuscitation of trauma patients: a review of prehospital transfusion practices and a description of our regional whole blood program in San Antonio, TX. ISBT Sci Ser 2019;14:332-42.

15 Mapp JG, Bank EA, Osborn LA, Stringfellow ML, Reininger DW, Winckler CJ. Prehospital research and innovation in military and Expeditionary environments (prime) group. epidemiological and accounting analysis of ground ambulance whole blood transfusion. Prehosp Disaster Med 2020;35:98-103.

16 Schaefer R, Long T, Wampler D, Summers R, Epley E, Waltman E, Eastridge B, Jenkins D. Operationalizing the deployment of low-titer O-Positive whole blood within a regional trauma system. Mil Med 2021;186:391-9.

17 Roberts I, Shakur H, Coats T, Hunt B, Balogun E, Barnetson L, Cook L, Kawahara T, Perel P, Prieto-Merino D, et al. The CRASH-2 trial: a randomised controlled trial and economic evaluation of the effects of tranexamic acid on death, vascular occlusive events and transfusion requirement in bleeding trauma patients. Health Technol Assess 2013;17:1-79.

18 CRASH-3 trial collaborators. Effects of tranexamic acid on death, disability, vascular occlusive events and other morbidities in patients with acute traumatic brain injury (CRASH-3): a randomised, placebo-controlled trial. Lancet 2019;394:1713-23.

19 Rowell SE, Meier EN, McKnight B, Kanna D, May S, Sheehan K, Bulger EM, Idris AH, Christenson J, Morrison LJ, et al. Effect of Out-of-Hospital Tranexamic Acid vs Placebo on 6-Month Functional Neurologic Outcomes in Patients With Moderate or Severe Traumatic Brain Injury [published correction appears in JAMA. 2020 Oct 27;324(16):1683]. JAMA 2020;324:961-74. 